\title{
Multiple shape memory effects of polyimide nanocomposites based on octa(aminophenyl) silsequioxanes
}

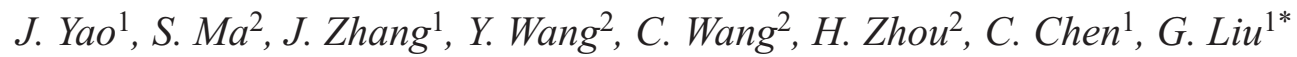 \\ ${ }^{1}$ Center for Advanced Low-Dimension Materials, State Key Laboratory for Modification of Chemical Fibers and Polymer \\ Materials, College of Materials Science and Engineering, Donghua University, 201600 Shanghai, China \\ ${ }^{2}$ National \& Local Joint Engineering Laboratory for Synthesis Technology of High Performance Polymer, Key Laboratory \\ of High Performance Plastics, Ministry of Education, College of Chemistry, Jilin University, 130012 Changchun, China
}

Received 29 June 2020; accepted in revised form 15 October 2020

\begin{abstract}
This work reports the synthesis of a series of shape memory polyimides by polycondensation of 2,2'-bis[4-(3aminophenoxy)phenyl]hexafluoropropane (m-6FBAPP), 4,4'-(hexafluoroisopropylidene) (6FDA) and PA-terminated OAPS. The influence upon shape memory properties by the introduction of PA-terminated OAPS was investigated systematically in both experiments and simulations. PA-terminated OAPS acted as both a plasticizer and a rigid cage structure, preventing excessive movement of the polymer chain. Thus, both strain and shape recovery values of the resulting polyimide composites strongly depended on the content of PA-terminated OAPS. The shape memory polyimide composites showed high strain and recovery values equal to 247 and $94.3 \%$, respectively. Additionally, these polyimide composites showed multiple shape memory effects and excellent shape memory cycle stability.
\end{abstract}

Keywords: smart polymers, shape memory effect, polyimides, octa(aminophenyl) silsequioxanes, nanocomposites

\section{Introduction}

Polyimides (PIs) possess excellent thermal stability, chemical and radiation resistance, mechanical and electrical stability, etc. Because of all these properties, polyimides are widely used for applications related to aerospace, microelectronics, coatings, and functional membranes [1-6]. Shape memory effects of PIs will broaden their applications even more so they can be used in harsh environments, such as deployable space structures, satellite antennae, solar arrays, smart jet propulsion, high-temperature sensors, and actuators, etc. [7-10]. Many strategies for achieving the PI shape memory were used, such as the incorporation of $\pi-\pi$ stacking to force $\pi-\pi$ interactions $[11,12]$, copolymerization $[9,13-18]$, chemical crosslinking [19-21], and hybridization [19, 22-24].

Strong $\pi-\pi$ interactions of polyimides lead to the high shape fixation rate $\left(R_{\mathrm{f}}\right)$ and high shape recovery rate $\left(R_{\mathrm{r}}\right)$ of the shape memory process. Wang et al. [12] prepared high-performance shape memory polyimide with $\pi$ - $\pi$ bonds using 3,3',4,4'-biphenyl tetracarboxylic (BPDA) and 4,4'-oxydianiline (ODA). The resulting PI demonstrated the presence of $\pi-\pi$ interactions and satisfactory shape memory effects. Kong and Xiao [11] reported excellent high-temperature cyclable shape memory PI capable of being deformed over 1000 cycles. Such excellent performance was because of $\pi-\pi$ interactions among the polyimide chains. Incorporating rigid moieties into flexible polyimide backbones using random copolymerization should result in a material with excellent shape memory performance. The rigid structure as a permanent phase provides the shape recovery during the shape-memory-related processes and flexible structure as a temporary phase during the deformation [14]. Polyimides obtained by copolymerization have 
wide glass transition temperature ranges, which enable them to exhibit multiple shape memory effects. The shape memory effects of PIs can also be obtained by introducing a crosslinked structure into the flexible parts of their main chains. Similar to copolymerization, crosslinker in a memory polymer would act as a permanent phase, while the rest of the polymer fragments would serve as a temporary phase [23]. Shape memory PI-based hybrid materials are usually synthesized by in-situ polymerization of functionalized hybrid particles to provide the resulting materials with multiple types of responses or functionality. Yang et al. [21] reported shape memory polyimide/ silica composites with excellent thermal and mechanical properties and good atomic oxygen (AO) resistance. Koerner et al. [18] prepared shape mem tubes into the matrix. Lan et al. [25] prepared optically transparent thermoset PI composites containing polyhedral oligomeric silsesquioxanes (POSS). Many studies of shape-memory PIs with several different functionalities mostly focused on understanding how the incorporation of nanoparticles affected the shape memory properties. To resolve this oversight, this work focused on studying how the incorporation of OAPS into PI affects its shape memory properties. We also analyzed the shape-memory mechanism using molecular simulations.

Our previous work reported a weak shape memory effect of PIs synthesized using m-6FBAPP and 6FDA. These PIs showed low $R_{\mathrm{r}}$ value, which, however, can be adjusted using consequent crosslinking [26]. Thus, this paper describes how we introduced the cage structure into the PI chain to increase the shape memory effect. However, OAPS is octa-functional and tends to over-crosslink, which results in poor shape memory performance of the resulting composite PIs. Therefore, we functionalized some of the OAPS end groups with anhydride phthalic anhydride (PA). The PIs were then obtained by reacting PA-terminated OAPS with m-6FBAPP and 6FDA. The modified PIs possessed rigid cage structures with high $R_{\mathrm{r}}$ (up to $94.3 \%$ ) on the basis of maintaining high deformation and fixation rates because of the intrinsic properties of m-6FBAPP/6FDA-based PIs.

\section{Experimental section}

\subsection{Materials}

2,2'-Bis[4-(3-aminophenoxy)phenyl]hexafluoropropane (m-6FBAPP) and 4,4'-(hexafluoroisopropylidene) (6FDA) were supplied by Changzhou Sunlight
Pharmaceutical Co. Phthalic anhydride (PA) was acquired from Sinopharm Chemical Reagent Co. (China). Octa(aminophenyl)-silsequioxane (OAPS) was purchased from Shanghai Gileader Advanced Materials Technology. N,N-dimethylacetamide (DMAc) was purified by distillation over $\mathrm{CaH}_{2}$ in a vacuum and stored over $4 \AA$ molecular sieve until further use.

\subsection{Preparation of POSS hybrid shape memory polyimides (SMPIs)}

The shape memory polyimides were prepared by a two-step process (see Figure 1). The synthesis of PI-1 was used as an example.

\subsubsection{Preparation of PA-terminated POSS precursor solution}

$1.000 \mathrm{mmol}(1.154 \mathrm{~g})$ of $\mathrm{NH}_{2}$-POSS and $6.000 \mathrm{mmol}$ $(0.889 \mathrm{~g})$ of PA were dissolved in $18.380 \mathrm{~g}$ of DMAc and stirred for $24 \mathrm{~h}$ at room temperature. PA-terminated POSS precursor solution with $10 \%$ solid content. The former precursor was dropwise added into sodium chloride solution to separate out in powder from, then the powder was vacuum freeze-dried to gain the PA-terminated POSS precursor.

\subsubsection{Preparation of polyamic acid (PAA) solution}

$3.992 \mathrm{mmol}(2.070 \mathrm{~g})$ of m-6FBAPP was placed into a $50 \mathrm{ml}$ round-bottom flask and dissolved in $21.23 \mathrm{~g}$ of DMAc. Then, $4.000 \mathrm{mmol}$ (1.777 g) of 6FDA was added to the mixture, which was then stirred for $2 \mathrm{~h}$ at room temperature.

\subsubsection{Preparation of POSS hybrid SMPI}

$0.008 \mathrm{mmol}(1.634 \mathrm{~g})$ of PA-terminated POSS precursor solution was added to the PAA solution and stirred for $12 \mathrm{~h}$ at room temperature. The solid content of the reaction system was controlled at $15 \%$ by weight. In the second stage, the POSS-containing PAA solution was cast on the glass plate and heated $60^{\circ} \mathrm{C} / 6 \mathrm{~h}$, $80^{\circ} \mathrm{C} / 6 \mathrm{~h}, 100^{\circ} \mathrm{C} / 4 \mathrm{~h}, 120^{\circ} \mathrm{C} / 4 \mathrm{~h}$, and $150^{\circ} \mathrm{C} / 1 \mathrm{~h}$ to remove the solvent. To complete the imidization, the film was then heated again at $150^{\circ} \mathrm{C} / 2 \mathrm{~h}, 200^{\circ} \mathrm{C} / 2 \mathrm{~h}$, $250^{\circ} \mathrm{C} / 1 \mathrm{~h}, 275^{\circ} \mathrm{C} / 1 \mathrm{~h}$ and $300^{\circ} \mathrm{C} / 1 \mathrm{~h}$ in a vacuum oven. PI-2, PI-3, and PI-4 materials were obtained by the same procedure using the initial material quantities listed in Table 1. All PAA solutions represented good intrinsic viscosity ranged from $0.3-0.4 \mathrm{dl} / \mathrm{g}$ and formed PI films with good performance. 

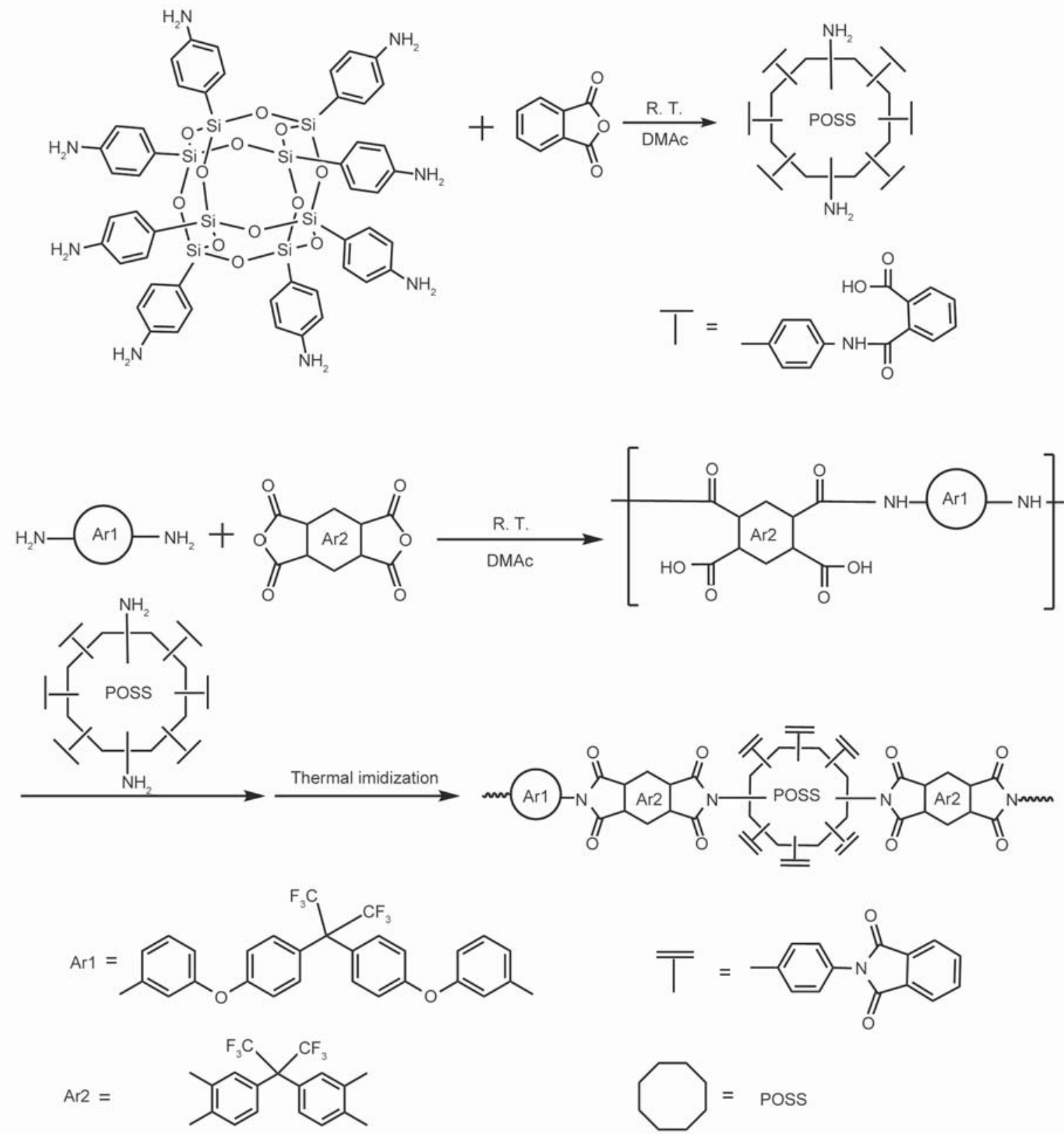

Figure 1. Synthesis of POSS-containing SMPI.

\subsection{Characterization}

FTIR spectra of thin PI films were recorded using Thermo Fisher Nicolet IS50 in the $400-4000 \mathrm{~cm}^{-1}$ range. Thermogravimetric analysis (TGA) was performed in $\mathrm{N}_{2}$ and air using a TA 2050 instrument. The heating rate was $10^{\circ} \mathrm{C} / \mathrm{min}$. DSC Q100 instrument was used to conduct differential scanning calorimetry (DSC) at $10{ }^{\circ} \mathrm{C} / \mathrm{min}$ heating rate and under constant $\mathrm{N}_{2}$ flow equal to $50 \mathrm{ml} / \mathrm{min}$. Differential mechanical analysis (DMA) was performed using DMA Q800, also fabricated by TA Instrument Co. (USA). Measurements were performed in the $50-280{ }^{\circ} \mathrm{C}$ range using a $5^{\circ} \mathrm{C} / \mathrm{min}$ scanning rate, $10 \mu \mathrm{m}$ amplitude, and $1 \mathrm{~Hz}$ load frequency of the film tension geometry. $T_{\mathrm{g}}$ was regarded as the peak of
Table 1. Content of initial materials used to prepare PI composites PI-0 through PI-4.

\begin{tabular}{|l|c|c|c|c|c|}
\hline & $\begin{array}{c}\text { OAPS } \\
{[\mathbf{m o l} \%]}\end{array}$ & $\begin{array}{c}\text { PA } \\
{[\mathbf{m o l} \%]}\end{array}$ & $\begin{array}{c}\text { m-6FBAPP } \\
{[\mathbf{m o l} \%]}\end{array}$ & $\begin{array}{c}\text { 6FDA } \\
{[\mathbf{m o l} \%]}\end{array}$ & $\begin{array}{c}\mathbf{\eta}^{\mathbf{a}} \\
{[\mathbf{d l} / \mathbf{g}]}\end{array}$ \\
\cline { 6 - 6 } & & & $\mathbf{P A A}$ \\
\hline PI-0 & 0 & 0 & 100.0 & 100 & 0.31 \\
\hline PI-1 & 0.2 & 1.2 & 99.8 & 100 & 0.40 \\
\hline PI-2 & 0.5 & 3.0 & 99.5 & 100 & 0.31 \\
\hline PI-3 & 1.0 & 6.0 & 99.0 & 100 & 0.31 \\
\hline PI-4 & 2.0 & 12.0 & 98.0 & 100 & 0.30 \\
\hline
\end{tabular}

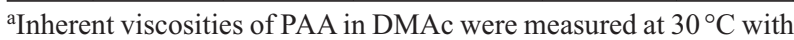
a concentration of $0.5 \mathrm{~g} / \mathrm{dl}$.

$\tan \delta$. Stress relaxation experiments were performed using the DMA Q800 setup. Samples were quickly stretched isothermally to $50 \%$ for $5 \mathrm{~min}$ at $T_{\mathrm{g}}+20^{\circ} \mathrm{C}$. 
The residual strain was measured for $60 \mathrm{~min}$, after which the external force was removed. The geometry optimization of PI polymer chain with 20 repeating units was carried out by the Materials Studio 2017 program using Forcite-based calculations.

Shape memory tests were performed using the Q800 instrument fabricated by TA Instruments (USA) using rectangular $20 \times 3.0 \times 0.09 \mathrm{~mm}$ samples. Shape memory cycling was performed using tension clamps and a controlled force mode. The PI films were heated at $8^{\circ} \mathrm{C} / \mathrm{min}$ until their deformation temperature $\left(T_{\mathrm{d}}\right)$ was reached, after which the samples were stretched from $\varepsilon_{(\mathrm{N}-1)}$ (where $N$ is the number of cycles) to an elongation obtained at $T_{\mathrm{d}}$. The sample was kept for $5 \mathrm{~min}$ at $\varepsilon_{\text {load(N) }}$ and then was cooled at $8{ }^{\circ} \mathrm{C} / \mathrm{min}$ under the load until the fixation temperature $\left(T_{\mathrm{f}}\right)$ was reached. After the sample was unloaded, it returned to its temporary shape $\varepsilon_{(\mathrm{N})}$. The recovery procedure involved heating the sample back to the recovery temperature $T_{\mathrm{r}}$ (which was equal to $T_{\mathrm{d}}$ in this work) to obtain $\varepsilon_{\mathrm{re}(\mathrm{N})}$. Thermally-induced shape-memory behavior of PIs was evaluated using the shape fixation $\left(R_{\mathrm{f}}\right)$ and recovery $\left(R_{\mathrm{r}}\right)$ rates, calculated using the Equation (1) and (2) [28]:

$R_{\mathrm{f}}=\frac{\varepsilon_{(\mathrm{N})}-\varepsilon_{(\mathrm{N}-1)}}{\varepsilon_{\text {load }(\mathrm{N})}-\varepsilon_{(\mathrm{N}-1)}} \cdot 100 \%$

$R_{\mathrm{r}}=\frac{\varepsilon_{(\mathrm{N})}-\varepsilon_{\mathrm{re}(\mathrm{N}-1)}}{\varepsilon_{(\mathrm{N})}-\varepsilon_{(\mathrm{N}-1)}} \cdot 100 \%$

where $\varepsilon_{\text {load }}$ is the maximum strain during deformation under the load, $\varepsilon$ is the fixed strain after cooling and unloading, $\varepsilon_{\mathrm{re}}$ is the strain after recovering, and $N$ is the step number. The illustration of the dual-shape memory process was shown in Figure 2.

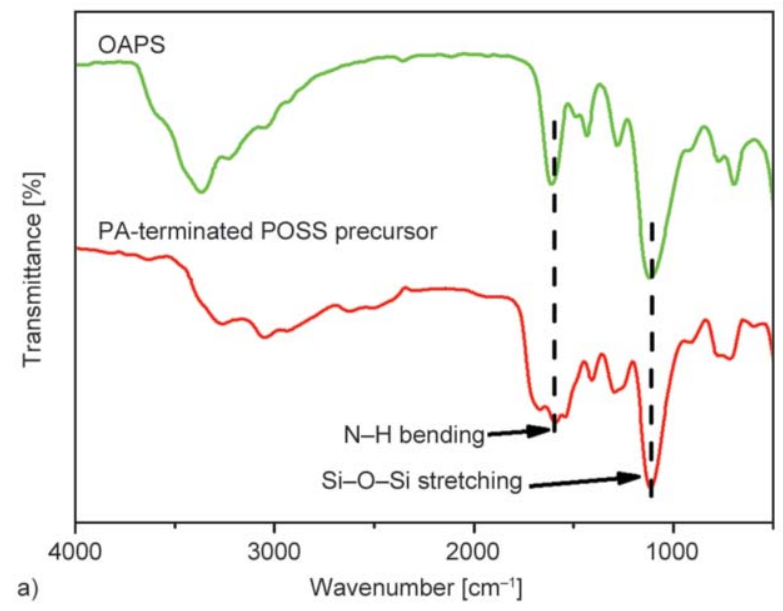

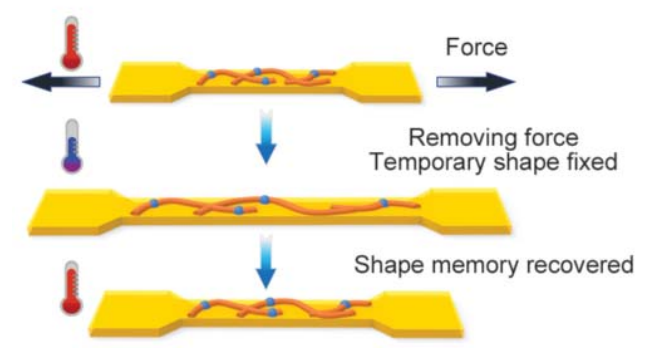

Figure 2. Dual-shape memory process of POSS-containing SMPI.

\section{Results and discussion}

\subsection{Preparation of POSS hybrid shape memory polyimides (POSS-hybrid SMPIs)}

PI-1 4 materials were prepared by co-polycondensation of OAPS, PA, m-6FBAPP, and 6FDA using corresponding stoichiometric ratios of amine and anhydride to achieve high molecular weight. The structure of these materials was analyzed by FTIR. Peaks at $1100 \mathrm{~cm}^{-1}$ indicated the Si-O of OAPS, 1600 $1620 \mathrm{~cm}^{-1}$ corresponded to the $\mathrm{N}-\mathrm{H}$ bond represented the exist of amino group both in OAPS and PA-terminated POSS (Figure 3a). Absorption bands at $\sim 1110-1260$ and $750-790 \mathrm{~cm}^{-1}$ (which correspond to $\mathrm{Si}-\mathrm{O}-\mathrm{Si}$ and $\mathrm{Si}-\mathrm{C}$ stretching vibrations) observed in the FTIR spectra of PI-1 4 materials suggested that the OAPS was successfully introduced into the polyimide backbone. Furthermore, the disappearance of bands at $3200-3450$ and $1500-1620 \mathrm{~cm}^{-1}$ (which correspond to the $\mathrm{N}-\mathrm{H}$ stretching and bending vibrations, respectively) indicated that PI-0 4 were fully imidized (Figure 3b).

\subsection{Morphology of POSS-hybrid PIs}

The particle sizes of POSS fragments were 1-2 $\mu \mathrm{m}$ (see Figure 4a). The typical polymer cross-section

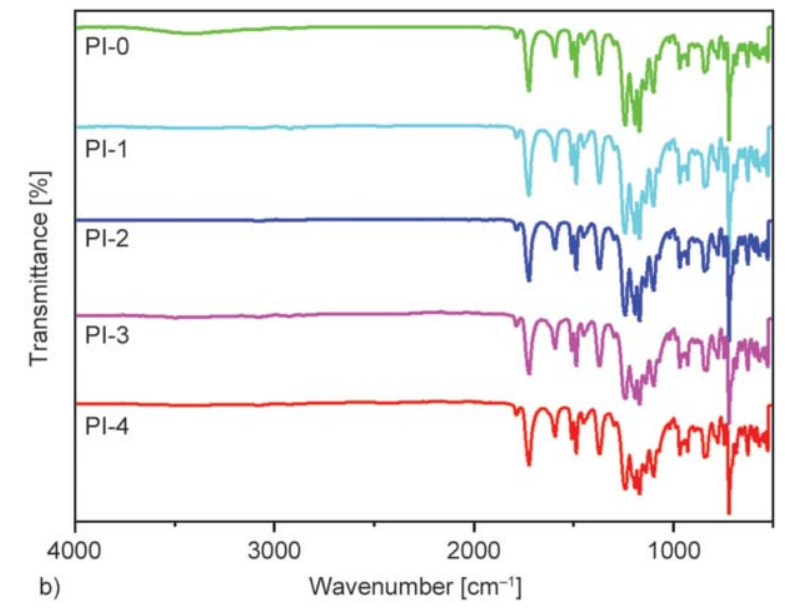

Figure 3. FTIR spectra of OAPS, PA-terminated POSS (a), and POSS-hybrid SMPIs (b). 
possessed morphology similar to the fish scales. Pure PI matrix of PI-0 exhibited a smooth surface in Figure $4 \mathrm{~b}$, POSS particles were evenly distributed in the polyimide matrix, indicating that POSS was successfully introduced into the polyimide main chain, which agrees with FTIR results. POSS showed a homogeneous dispersion inside the hybrid system with uniform morphology (Figure $4 \mathrm{c}$ and $4 \mathrm{~d}$ ). The polyimide films were transparent and smooth, even after the introduction of POSS (Figure $9 b$ ).

\subsection{Thermal properties of POSS-hybrid PIs}

Polyimides synthesized in this work exhibited excellent thermal properties (see Table 2). PI-0 4 demonstrated excellent thermal stability with $T_{\mathrm{d} 5 \%}$ and $T_{\mathrm{d} 10 \%}$ values in the $510-529$ and $530-545^{\circ} \mathrm{C}$ ranges, under nitrogen, respectively (Figure 4a). The char yield of all polyimides was more than $50 \%$, which further confirms the excellent thermal stability of PIs synthesized in this work. The thermal stability of polyimides was in the following order of PI- $0>\mathrm{PI}-1>$ PI-2 > PI-3 > PI-4, which also corresponds to the order of their thermal oxidation stability (Figure 4b). Such excellent behavior was observed because of the

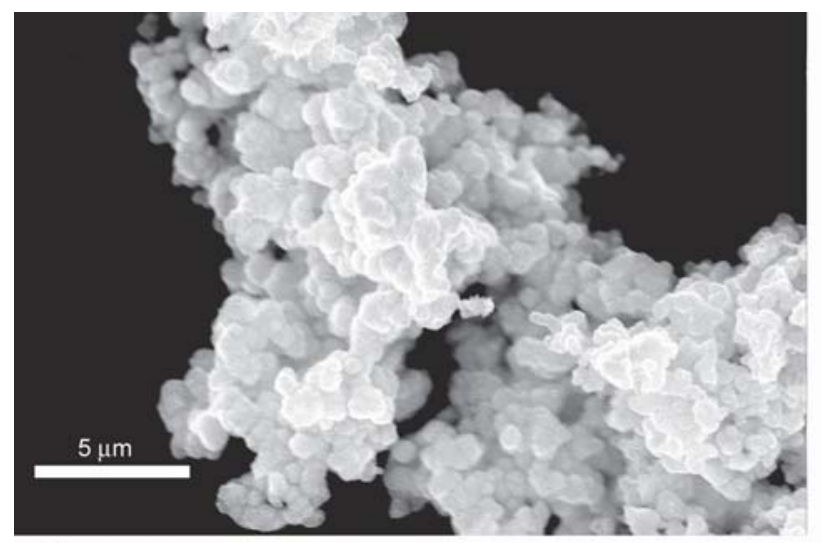

a)

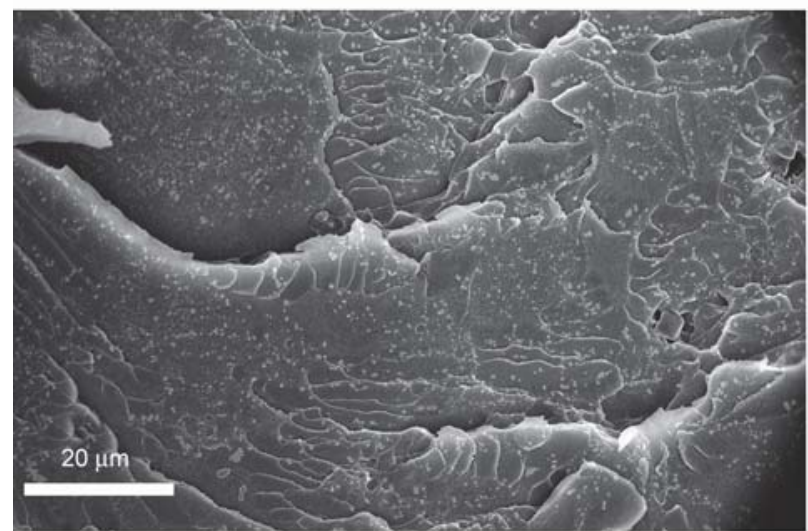

c) insertion of OAPS cage fragments between the macromolecular chains, which, in turn, expanded the spacings between the chains, reducing their $\pi-\pi$ interactions. Thus, PA-terminated OAPS acted as a plasticizer. The thermal stability of the PI composites decreased as the content of PA-terminated OAPS increased. $T_{\mathrm{g}}$ values of the shape memory polyimides determined by DSC and DMA were in the 212-220 and $222-233^{\circ} \mathrm{C}$ ranges, respectively. The $T_{\mathrm{g}}$ of obtained by DSC was in the following order: PI- $0>$ PI$1>\mathrm{PI}-2>\mathrm{PI}-3>\mathrm{PI}-4$ (see Figure $5 \mathrm{c}$ ). The $T_{\mathrm{g}}$ of a polymer depends on the polymeric chain rigidity and packing density. The difference in $T_{\mathrm{g}}$ values between PI composites synthesized in this work was small. Thus, the introduction of small quantities of PI-terminated OAPS barely affected the stiffness of the main PI chain. Therefore, the high $T_{\mathrm{g}}$ of the initial polymeric chain remained at its almost original level. $T_{\mathrm{g}}$ values obtained by DMA were slightly different from those obtained by DSC. POSS-hybrid SMPIs also possessed high initial storage moduli (in the 1500-2500 MPa range at low temperatures, see Figure $5 \mathrm{~d}$ ). The storage modulus remained the same below $T_{\mathrm{g}}$. In addition, the storage modulus of PI

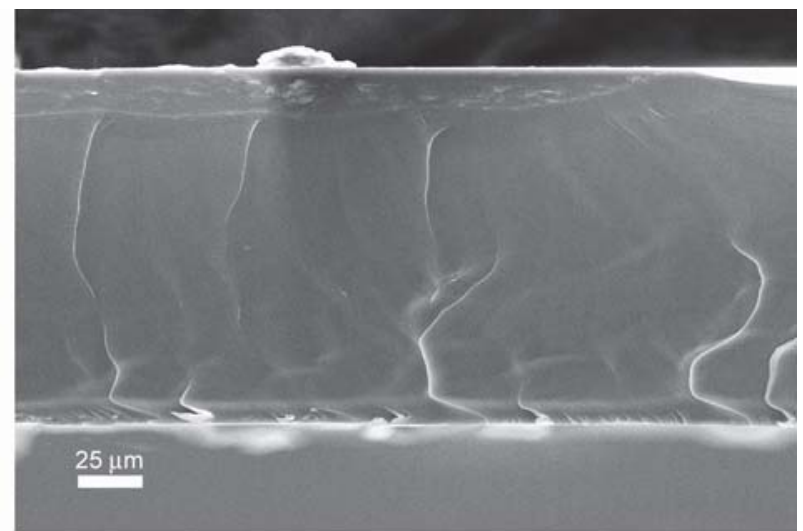

b)

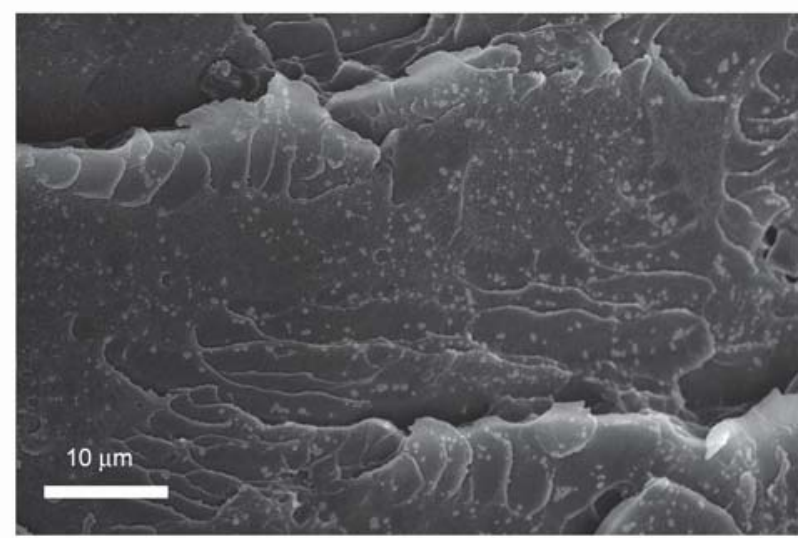

d)

Figure 4. SEM micrograph of OAPS particles (a), PI-0 (b), and PI-2 cross-section (c and d). 
Table 2. Thermal properties of POSS-hybrid SMPIs.

\begin{tabular}{|c|c|c|c|c|c|c|c|c|}
\hline & \multicolumn{2}{|c|}{$\begin{array}{c}T_{\mathrm{g}} \\
{\left[{ }^{\circ} \mathbf{C}\right]}\end{array}$} & \multicolumn{2}{|c|}{$\begin{array}{c}T_{\mathrm{d5} \%}{ }^{\mathrm{c}} \\
{\left[{ }^{\circ} \mathrm{C}\right]}\end{array}$} & \multicolumn{2}{|c|}{$\begin{array}{c}T_{\mathrm{d} 10 \%}{ }^{\mathrm{c}} \\
{\left[{ }^{\circ} \mathrm{C}\right]}\end{array}$} & \multirow{2}{*}{$\begin{array}{l}R_{\mathrm{w}}^{\mathrm{d}} \\
{[\%]}\end{array}$} & \multirow{2}{*}{$\begin{array}{c}\text { Relative stress relaxation } \\
{[\%]}\end{array}$} \\
\hline & $\mathrm{DSC}^{\mathrm{a}}$ & DMA $^{\mathbf{b}}$ & $\mathbf{N}_{2}$ & Air & $\mathbf{N}_{2}$ & Air & & \\
\hline PI-0 & 220 & 226 & 529 & 516 & 545 & 535 & 55 & 7.8 \\
\hline PI-1 & 219 & 233 & 521 & 506 & 537 & 525 & 51 & 10.3 \\
\hline PI-2 & 217 & 223 & 518 & 501 & 535 & 523 & 54 & 10.9 \\
\hline PI-3 & 214 & 231 & 516 & 488 & 534 & 515 & 54 & 19.9 \\
\hline PI-4 & 212 & 222 & 510 & 492 & 530 & 517 & 53 & 40.6 \\
\hline
\end{tabular}

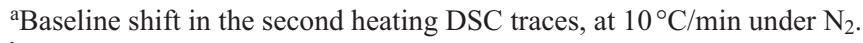

${ }^{\mathrm{b}} T_{\mathrm{g}}$ was regarded as the peak temperature of the $\tan \delta$.

${ }^{\mathrm{c}}$ Temperature corresponding to 5 and $10 \mathrm{wt} \%$ loss detected by TGA at $10^{\circ} \mathrm{C} / \mathrm{min}$ heating rate in $\mathrm{N}_{2}$ and air, respectively.

${ }^{\mathrm{d}}$ Residual weight retention at $800^{\circ} \mathrm{C}$ under $\mathrm{N}_{2}$.

${ }^{\text {e}}$ Relative stress relaxation maintained at $T_{\mathrm{g}}+20^{\circ} \mathrm{C}$ for 60 minutes.
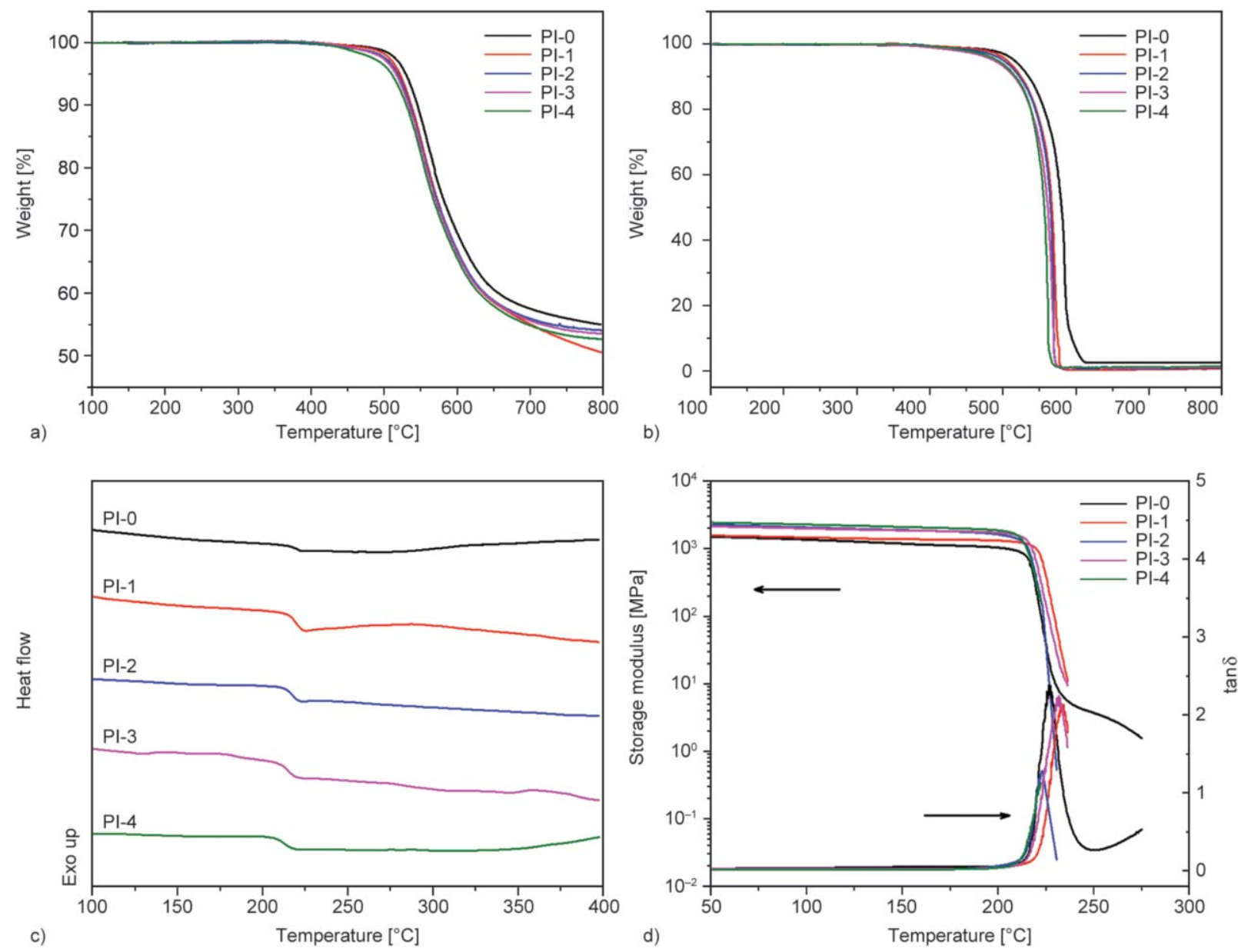

Figure 5. TGA curves of POSS hybrid SMPIs in the $\mathrm{N}_{2}$ (a), air (b), as well as their DSC (c) and DMA (d) curves.

composites sharply decreased (by almost three orders of magnitude) as the temperature increased, indicating the presence of shape memory effects [7].

\subsection{Shape memory effect of POSS-PIs}

Dual shape memory effects and parameters of polyimides are presented in Figure 6, and 7 and Table 3, respectively. All samples were stretched under the same external force $(0.05 \mathrm{~N})$ during the dual-memory test process. The shape memory of PI-0, reported in previous work [26], occurred because of the flexible structure of the polymer chain. Therefore, PI-0 demonstrated high strain and high $R_{\mathrm{f}}$, but low $R_{\mathrm{r}}$ (only $85.1 \%$ ). The introduction of PA-terminated OAPS into the PI backbone caused the strain of the resulting composite to increase from 97 to $242 \%$ under the same static force, which, in turn, increased $R_{\mathrm{r}}$ value from 85.1 to $94.3 \%$ but barely affected $R_{\mathrm{f}}$. At 


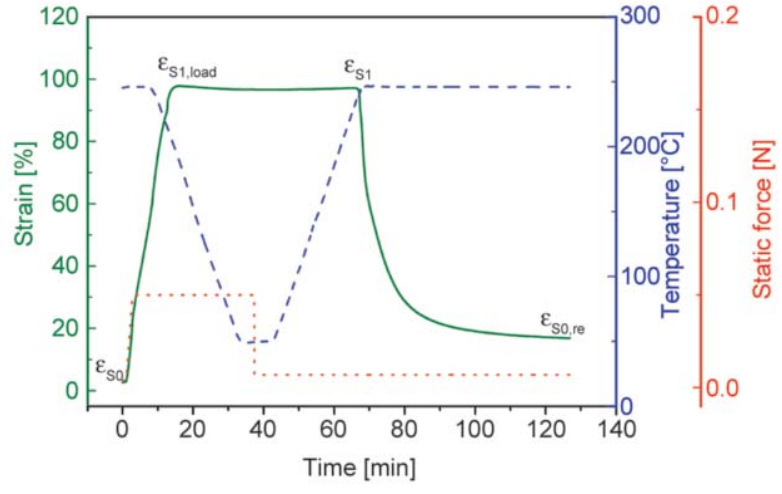

Figure 6. Dual shape memory effects of PI-0 $\left(T_{\mathrm{d}}=T_{\mathrm{r}}=\right.$ $\left.T_{\mathrm{g}}+20^{\circ} \mathrm{C}, T_{\mathrm{f}}=50^{\circ} \mathrm{C}\right)$.

OAPS content equal to $2 \%$, the deformation of the material decreased to $97 \%$. The recovery rate decreased as well. Therefore, the addition of a small amount of PA-terminated OAPS acted as a plasticizer and increased the deformation capacity of the resulting PI composites [27]. Too many rigid cage fragments in the PI chain would be detrimental to the PI strain needed for the shape memory process. Incorporation of a small amount of PA-terminated OAPS with a rigid cage structure should provide the whole polymer with high $R_{\mathrm{r}}$ during PI deformation. Therefore, PI-3, which contained $1 \%$ of PA-terminated OAPS, possessed the best shape memory properties among all other PI synthesized in this work. Strain,

Table 3. Dual shape memory parameters of polyimides.

\begin{tabular}{|c|r|c|c|}
\hline & $\begin{array}{c}\text { Strain }^{\mathbf{a}} \\
{[\mathbf{\%}]}\end{array}$ & $\begin{array}{c}\boldsymbol{R}_{\mathbf{f}}^{\mathbf{b}} \\
{[\mathbf{\%}]}\end{array}$ & $\begin{array}{c}\boldsymbol{R}_{\mathbf{r}}^{\mathbf{b}} \\
{[\mathbf{\%}]}\end{array}$ \\
\hline PI-0 & 97 & 98.7 & 85.1 \\
\hline PI-1 & 130 & 98.8 & 90.9 \\
\hline PI-2 & 191 & 99.0 & 90.6 \\
\hline PI-3 & 242 & 99.0 & 94.3 \\
\hline PI-4 & 97 & 98.7 & 92.6 \\
\hline
\end{tabular}

${ }^{a}$ Tensile strain, $\varepsilon$;

${ }^{\mathrm{b}}$ Shape fixity ratio, $R_{\mathrm{f}}$ and shape recovery ratio, $R_{\mathrm{r}}$.

$R_{\mathrm{f}}$, and $R_{\mathrm{r}}$ values of PI-3 were equal to $242,99.0$, and $94.3 \%$, respectively.

A step-wide temperature increase during testing of our PIs resulted in an unusual step-wise recovery behavior, which suggests that these materials 'memorized' multiple temporary shapes with just one shape memory cycle. Thus, multiple shape memory effects were achieved [28-31]. The excellent dual shape memory effect of PI-3 encouraged us to study its multiple shape memory performances. Figure 8 exhibits the multi-staged shape recovery of PI-3, which deformed at $270^{\circ} \mathrm{C}$ and fixed at $150^{\circ} \mathrm{C}$. The sample yielded a temporary shape with a $123 \%$ strain. The shape recovered at $230,240,250,260$ and $270^{\circ} \mathrm{C}$, respectively.

Triple shape memory effects of PI-3 are shown in Figure 9. The initial permanent shape (S0) was de-
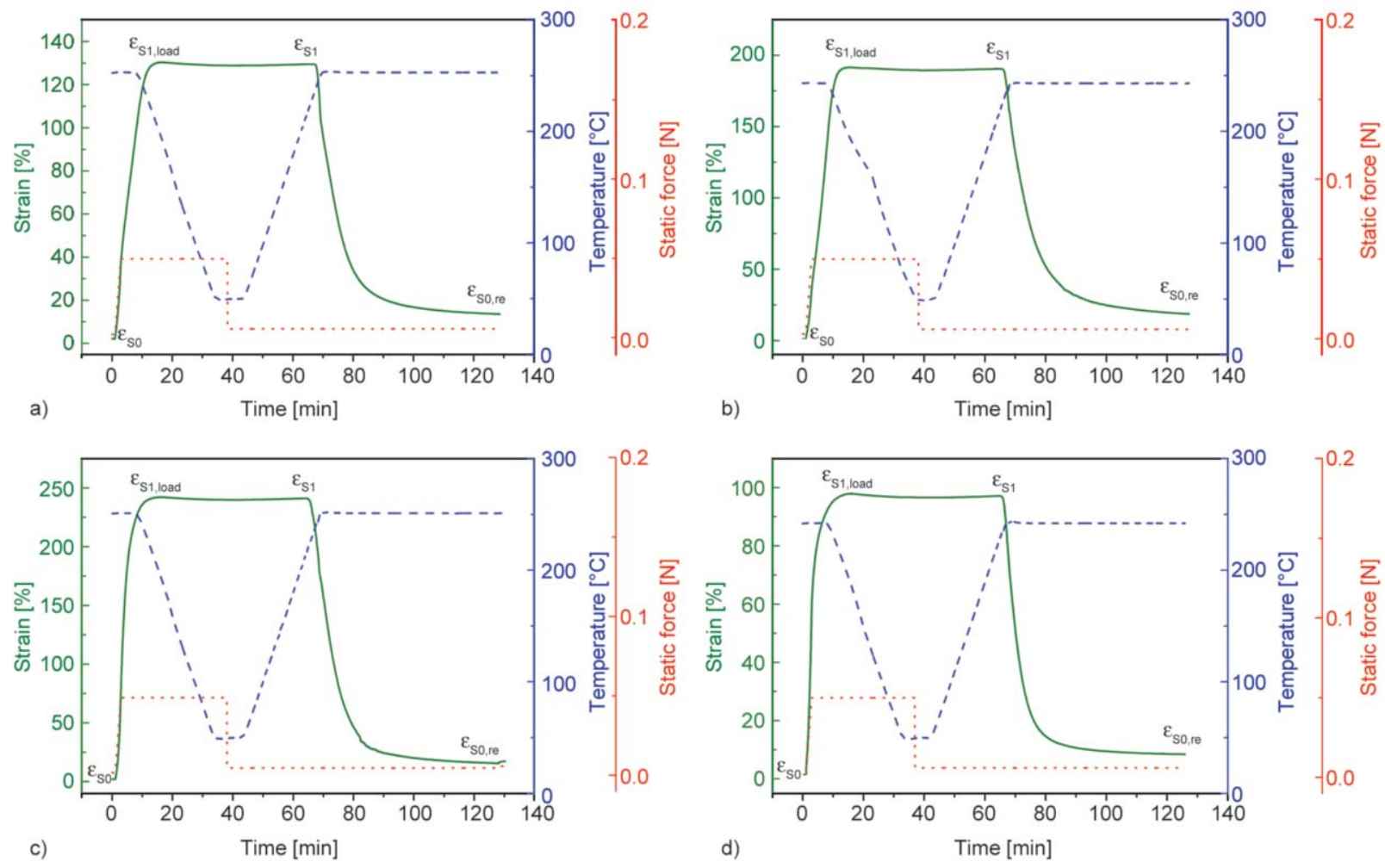

Figure 7. Dual shape memory effects of PI-1 (a), PI-2 (b), PI-3 (c), PI-4 (d), $\left(T_{\mathrm{d}}=T_{\mathrm{r}}=T_{\mathrm{g}}+20^{\circ} \mathrm{C}, T_{\mathrm{f}}=50^{\circ} \mathrm{C}\right)$. 


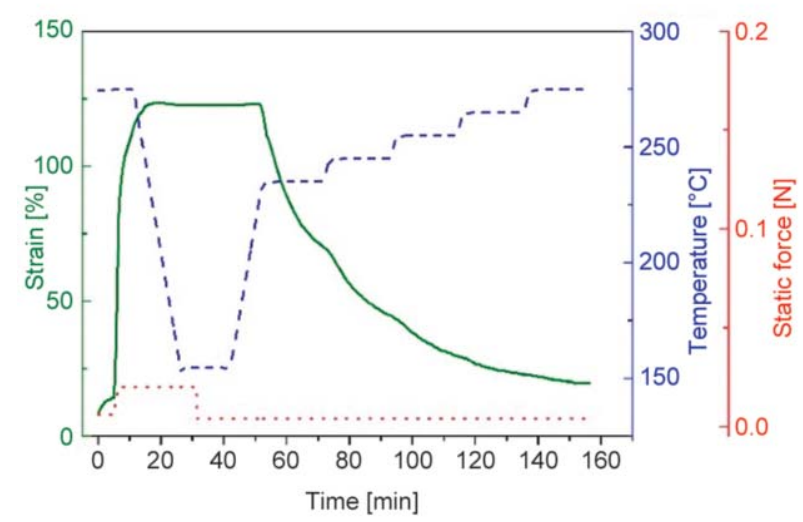

Figure 8. Multi-staged shape recovery of PI-3 $\left(T_{\mathrm{d}}=270^{\circ} \mathrm{C}\right.$, $\left.T_{\mathrm{f}}=150^{\circ} \mathrm{C}, T_{\mathrm{r}}=230+240+250+260+270^{\circ} \mathrm{C}\right)$.

formed at $270^{\circ} \mathrm{C}$ and then fixed at $230^{\circ} \mathrm{C}$ yielding the first temporary shape (S1) with a $97 \%$ strain and $72.2 \% R_{\mathrm{f} 1}$ value. The polyimide further deformed at $230^{\circ} \mathrm{C}$ and fixed at $150^{\circ} \mathrm{C}$ to yield the second temporary shape (S2) with $176 \%$ strain and $99.7 \% R_{\mathrm{f} 2}$ value. Upon reheating, as the temperature was increased from 150 to 230 and then to $270{ }^{\circ} \mathrm{C}$, the strain was recovered step-by-step. The $R_{\mathrm{r}}$ of each step was 104.4 and $55 \%$, which indicates a typical triple-shape memory behavior. Moreover, the practicality picture during the triple-shape memory process was shown in Figure 9b; its deformation-recovery appearance highly convinced the application of our shape memory polyimides, especially for its multiple shape memory behaviors triggered via high temperature.

\subsection{Shape memory cycles of SMPIs}

Cycling performances of the shape memory cycle of PIs synthesized in this work are shown in Figure 10 and 11. Corresponding cycling parameters are listed in Table 4 . The strain of PI- $0 \sim 3$ samples increased 1-3 times after four shape memory cycles performed under the same force of $0.03 \mathrm{~N}$ (see Figure 10). However, PI-4 demonstrated the highest strain stability, with the strain ranging from 78 to $82 \%$ after
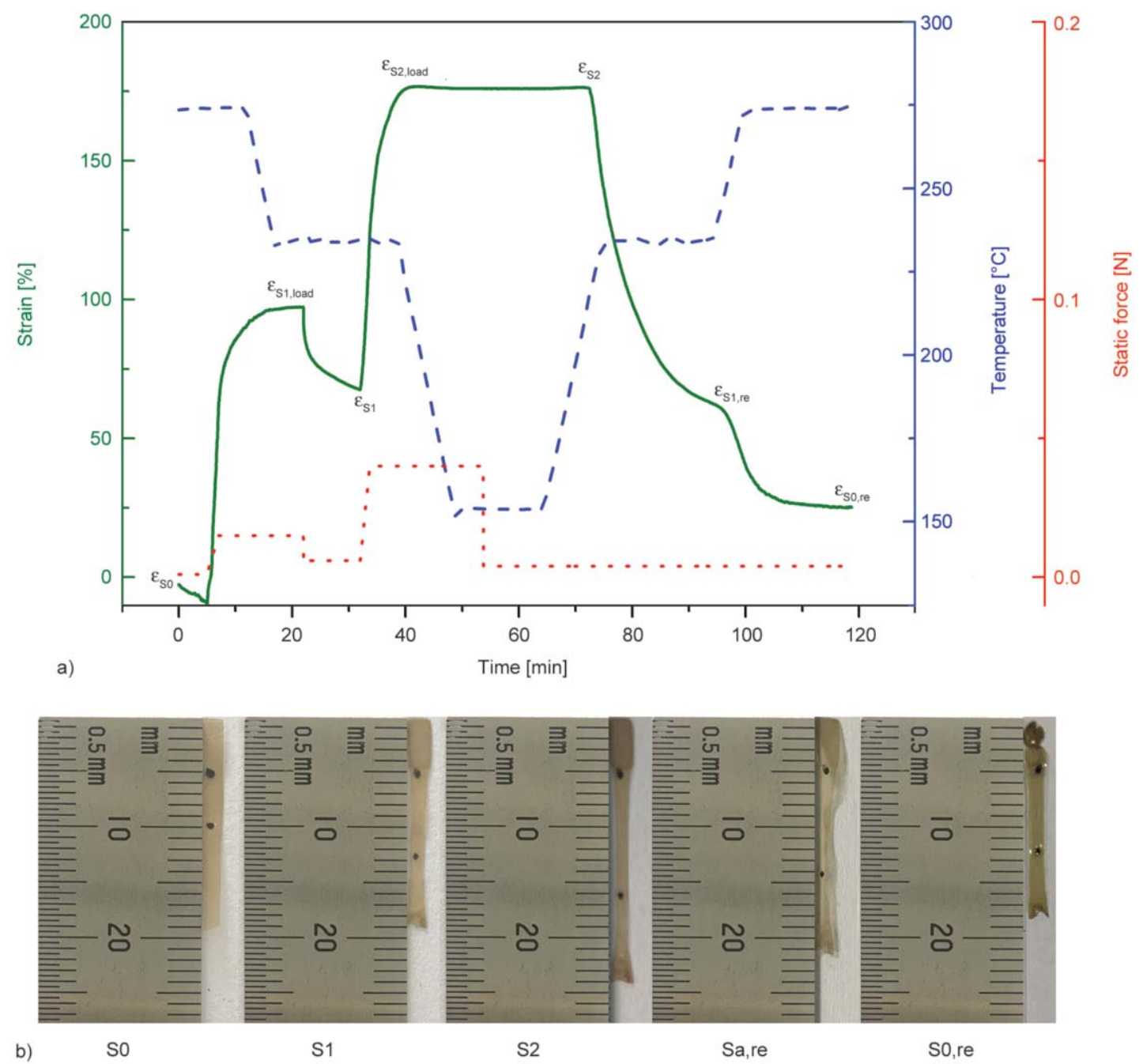

Figure 9. (a) Triple shape memory properties of PI-3 composite with deformation and recovery temperatures of $270+230{ }^{\circ} \mathrm{C}$. $\varepsilon_{\mathrm{S} 1, \text { load }}=97 \%, \varepsilon_{\mathrm{S} 2, \text { load }}=176 \%, R_{\mathrm{f}(\mathrm{S} 0 \rightarrow \mathrm{S} 1)}=72.2 \%, R_{\mathrm{f}(\mathrm{S} 1 \rightarrow \mathrm{S} 2)}=99.7 \%, R_{\mathrm{r}(\mathrm{S} 2 \rightarrow \mathrm{S} 1)}=104.4 \%, R_{\mathrm{r}(\mathrm{S} 1 \rightarrow \mathrm{S} 0)}=55.0 \%$. (b) Demonstration of triple-SME of PI-3. 


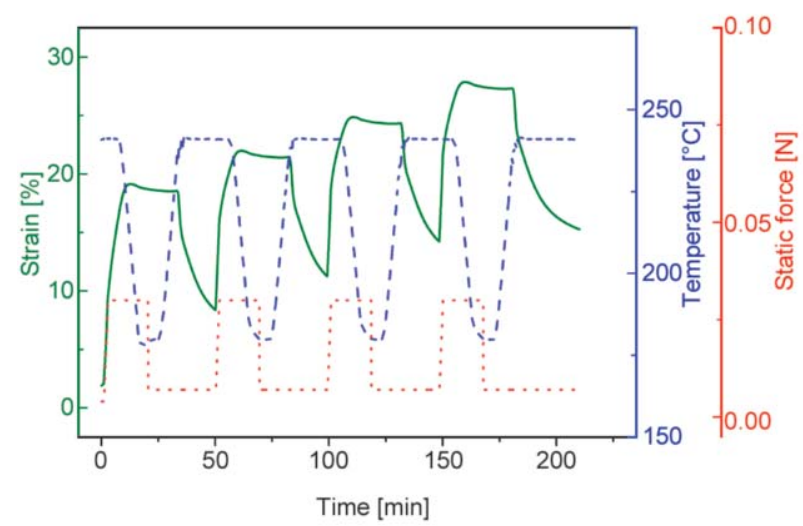

Figure 10. Shape memory cycles of PI-0 $\left(T_{\mathrm{d}}=T_{\mathrm{r}}=\right.$ $\left.T_{\mathrm{g}}+15^{\circ} \mathrm{C}, T_{\mathrm{f}}=180^{\circ} \mathrm{C}\right)$.

four cycles. Higher $R_{\mathrm{f}}$ values were observed for PIs equal to $99.2-99.8 \%$. The trend of the obviously increasing residual strain for the PI-0 2 materials continued over several shape recovery cycles because of the decreased chain relaxation capability. During cycling, some polymer chain entanglements destruction inevitably occurred, which led to the hysteresis. The residual strains of PI-3 and PI-4 samples in each cycle were relatively stable and low because of large deformation. PI-0 showed a poor recovery rate because the conventional chain entanglements prevented plastic flow and led to low $R_{\mathrm{r}}$ [26]. Comparing to PI-0 2, PI-3 and PI-4 (which possessed higher OAPS contents) exhibited higher recovery rates after four
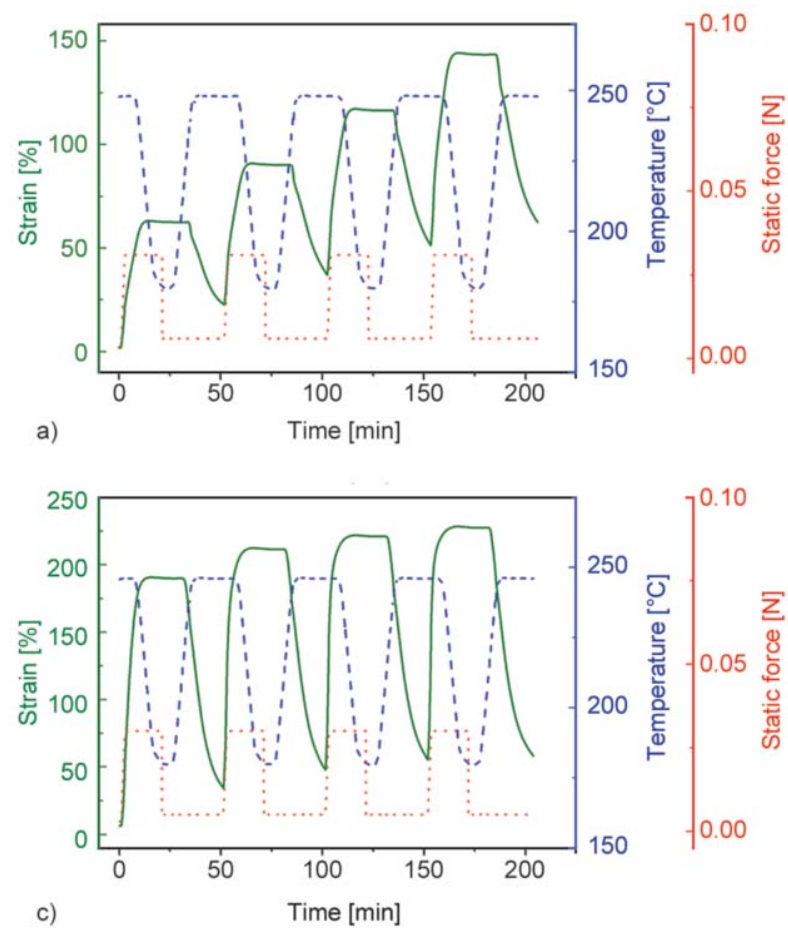

Table 4. Shape memory cycle parameters of polyimides.

\begin{tabular}{|c|c|c|c|c|c|}
\hline \multicolumn{2}{|c|}{ Title Cycle } & 1 & 2 & 3 & 4 \\
\hline \multirow{4}{*}{ PI-0 } & Strain $^{\mathrm{a}}$ & 84 & 163 & 243 & 323 \\
\hline & $R_{\mathrm{f}}^{\mathrm{b}}$ & 99.3 & 99.5 & 99.7 & 99.7 \\
\hline & $R_{\mathrm{r}}^{\mathrm{b}}$ & 58.9 & 72.6 & 79.9 & 79.7 \\
\hline & Residual strain $^{\mathrm{a}}[\%]$ & 35 & 69 & 104 & 148 \\
\hline \multirow{4}{*}{ PI-1 } & Strainí & 63 & 90 & 117 & 144 \\
\hline & [\%] & 99.2 & 99.2 & 99.3 & 99.3 \\
\hline & [\%] & 66.0 & 78.7 & 82.1 & 87.7 \\
\hline & Residual strain [\%] & 23 & 37 & 51 & 63 \\
\hline \multirow{4}{*}{ PI-2 } & Strain & 79 & 134 & 191 & 237 \\
\hline & [\%] & 99.5 & 99.6 & 99.6 & 99.6 \\
\hline & [\%] & 68.3 & 78.7 & 83.5 & 86.1 \\
\hline & Residual strain [\%] & 25 & 48 & 72 & 95 \\
\hline \multirow{4}{*}{ PI-3 } & Strain & 190 & 212 & 221 & 228 \\
\hline & [\%] & 99.7 & 99.6 & 99.6 & 99.6 \\
\hline & [\%] & 84.8 & 92.4 & 95.7 & 98.3 \\
\hline & Residual strain [\%] & 34 & 48 & 55 & 58 \\
\hline \multirow{4}{*}{ PI-4 } & Strain & 81 & 78 & 81 & 82 \\
\hline & {$[\%]$} & 99.6 & 99.2 & 99.8 & 99.4 \\
\hline & {$[\%]$} & 86.9 & 97.7 & 98.7 & 98.9 \\
\hline & Residual strain [\%] & 11 & 12 & 13 & 14 \\
\hline
\end{tabular}

${ }^{a}$ Tensile strain. $\varepsilon$;

${ }^{\mathrm{b}}$ Shape fixity ratio, $R_{\mathrm{f}}$ and shape recovery ratio, $R_{\mathrm{r}}$.

cycles: 98.3 and $98.9 \%$, respectively. Moreover, as irreversible deformation disappeared during the previous cycle, the $R_{\mathrm{r}}$ increased with the number of cycles.

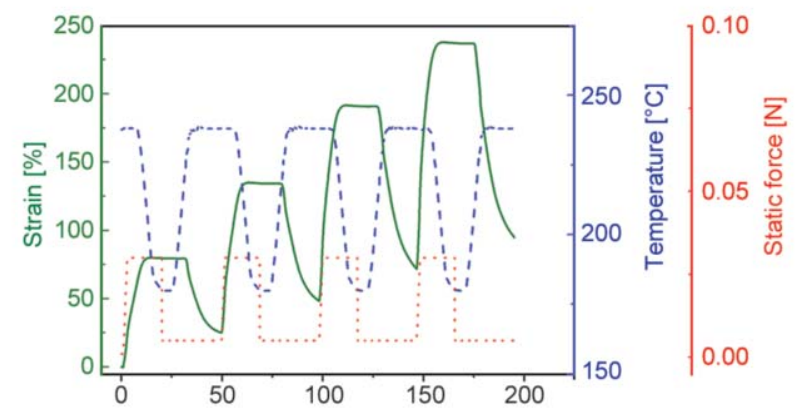

b)

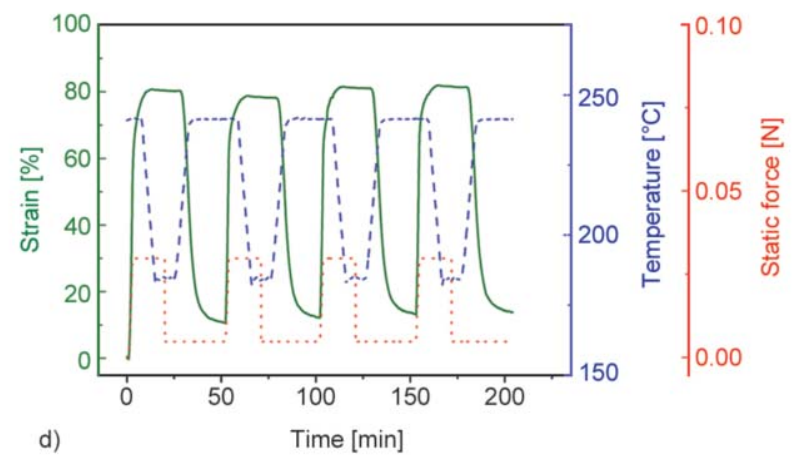

Figure 11. Shape memory cycles of PI-1 (a), PI-2 (b), PI-3 (c), and PI-4 (d) composites $\left(T_{\mathrm{d}}=T_{\mathrm{r}}=T_{\mathrm{g}}+15^{\circ} \mathrm{C}, T_{\mathrm{f}}=180^{\circ} \mathrm{C}\right)$. 


\subsection{Molecular simulations of POSS-hybrid SMPI}

To investigate the relationship between the structure and shape memory properties of polyimides, the geometry of a molecular chain containing 20 repeating units of both initial and POSS-modified PI (POSS-hybrid SMPI) was optimized using Materials Studio 2017 (see Figure 12) [32]. Unmodified PI had a large number of entangled chains, which very likely was beneficial for the high strain of shape memory processes, but resulted in poor shape recovery. Comparing to unmodified PI, the structure of the POSShybrid PI showed looser chain segment packing and longer chain sequences. Moreover, the rigid cage structure of OAPS disrupted the close chain entanglements, resulting in a large free volume inside POSS-hybrid SMPI [33]. These results further verified that OAPS not only played a plasticizing role in shape memory but also provided a restoring force during the shape memory recovery.

\subsection{Stress relaxation of POSS-hybrid PIs}

The cyclic tensile tests indicated that each PI deformation recovery process was accompanied by the stress release. Thus, the deformation of the shape memory was closely related to the stress relaxation. The normalized stress relaxation curves are shown in Figure 13. All samples were quickly stretched to $50 \%$ strain at $T_{\mathrm{g}}+20^{\circ} \mathrm{C}$, and the strain was maintained for $300 \mathrm{~s}$. All POSS hybrid SMPIs displayed high relaxation rates, indicating that these PIs could be quickly returned to their original shapes. In addition, as OPAS content in PIs increased, their stress re-

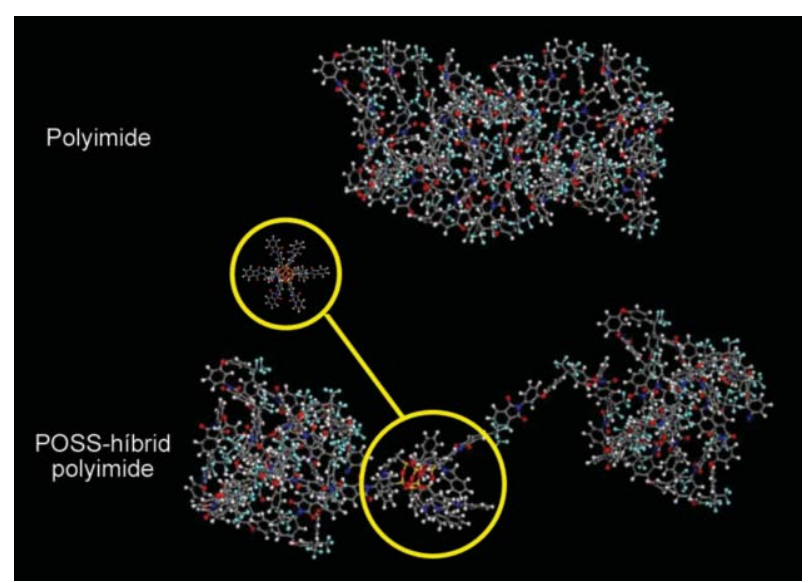

Figure 12. Molecular simulation of SMPI and POSS-modified PI (POSS-hybrid SMPI) containing 20 repeating units.

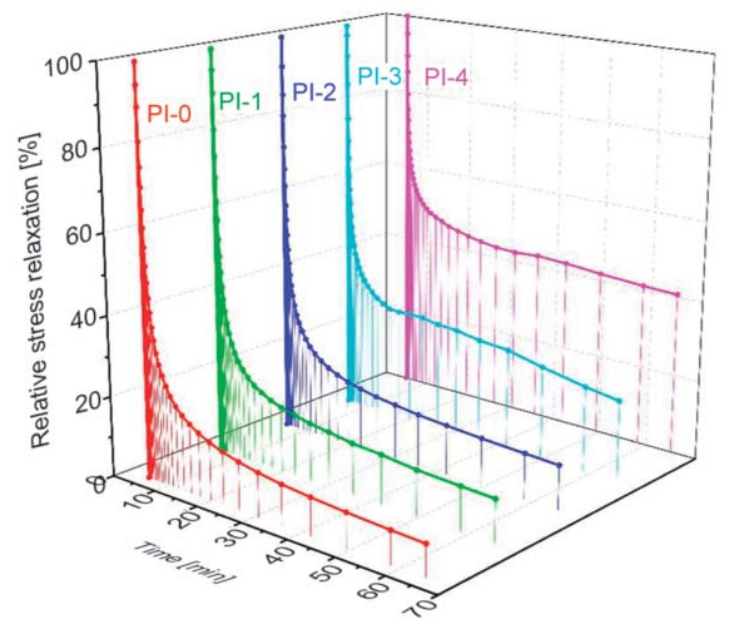

Figure 13. Relative stress relaxation of polyimides at $T_{\mathrm{g}}+20^{\circ} \mathrm{C}$.

laxation degrees decreased, relative stress relaxation increased from 7.8 to $40.6 \%$, which led to higher elastic energy storage capacity and a more significant recovery force during the shape recovery process. Excessive content of rigid OAPS would limit the material deformation. Thus, incorporation of only $1 \%$ of OAPS provided PIs synthesized in this work with excellent shape memory performance.

\section{Conclusions}

This paper describes the synthesis of POSS-hybrid shape memory polyimides synthesized using copolymerization of m-6FBAPP, 6FDA, and PA-terminated OPAS. The PA-terminated OAPS precursor solution was set up as 1:6 of OAPS:PA based on feeding ratio. POSS showed a homogeneous dispersion inside the hybrid system. We fabricated smooth and homogeneous PI films, which demonstrated high thermal stability with $T_{\mathrm{d} 5 \%}$ and $T_{\mathrm{d} 10 \%}$ values in the 510-529 and $530-545^{\circ} \mathrm{C}$ ranges, respectively. The incorporation of cage-structured OAPS disrupted the close chain entanglements of PIs, which resulted in the formation of free volume inside the POSS-hybrid SMPIs. Several shape memory effects with high strain were achieved for the organic-inorganic polyimides for the first time. The strain and $R_{\mathrm{r}}$ could be adjusted by changing the content of PA-terminated OAPS. POSS-hybrid SMPIs with 1\% OPAS content possessed good shape memory and high shape memory cycle stability, with the strain, $R_{\mathrm{f}}$, and $R_{\mathrm{r}}$ values equal to 242,99 , and $94.3 \%$. 


\section{References}

[1] Liaw D-J., Wang K-L., Huang Y-C., Lee K-R., Lai J-Y., Ha C-S.: Advanced polyimide materials: Syntheses, physical properties and applications. Progress in Polymer Science, 37, 907-974 (2012).

https://doi.org/10.1016/j.progpolymsci.2012.02.005

[2] Jiang L. Y., Wang Y., Chung T-S., Qiao X. Y., Lai J-Y.: Polyimides membranes for pervaporation and biofuels separation. Progress in Polymer Science, 34, 11351160 (2009).

https://doi.org/10.1016/j.progpolymsci.2009.06.001

[3] Guan Y., Wang D., Wang Z., Dang G., Chen C., Zhou H., Zhao X.: Synthesis and characterization of novel polyimides from 4,4'-bis(5-amino-2-pyridinoxy)diphenyl ether, 4,4'-bis(5-amino-2-pyridinoxy)diphenyl thioether and 4,4'-bis(5-amino-2-pyridinoxy)diphenyl sulfone. RSC Advances, 4, 50163-50170 (2014).

https://doi.org/10.1039/c4ra07855a

[4] Wang S., Ma S., He H., Ai W., Wang D., Zhao X., Chen C.: Aromatic polyimides containing pyridine and spirocyclic units: Preparation, thermal and gas separation properties. Polymer, 168, 199-208 (2019).

https://doi.org/10.1016/j.polymer.2019.02.046

[5] Wu Q., Ma X., Zheng F., Lu X., Lu Q.: Synthesis of highly transparent and heat-resistant polyimides containing bulky pendant moieties. Polymer International, 68, 1186-1193 (2019).

https://doi.org/10.1002/pi.5811

[6] Chow W. S., Ishak Z. A.: Smart polymer nanocomposites: A review. Express Polymer Letters, 14, 416-435 (2020).

https://doi.org/10.3144/expresspolymlett.2020.35

[7] Gao H., Lan X., Liu L., Xiao X., Liu Y., Leng J.: Study on performances of colorless and transparent shape memory polyimide film in space thermal cycling, atomic oxygen and ultraviolet irradiation environments. Smart Materials and Structures, 26, 095001/1-095001/13 (2017).

https://doi.org/10.1088/1361-665X/aa7bd7

[8] Xiao X., Kong D., Qiu X., Zhang W., Liu Y., Zhang S., Zhang F., Hu Y., Leng J.: Shape memory polymers with high and low temperature resistant properties. Scientific Reports, 5, 14137/1-14137/12 (2015).

https://doi.org/10.1038/srep14137

[9] Gao H., Xie F., Liu Y., Leng J.: Effects of $\gamma$-radiation on the performances of optically transparent shape memory polyimides with a low glass transition temperature. Polymer Degradation and Stability, 156, 245-251 (2018). https://doi.org/10.1016/j.polymdegradstab.2018.09.014

[10] Xiao X., Qiu X., Kong D., Zhang W., Liu Y., Leng J.: Optically transparent high temperature shape memory polymers. Soft Matter, 12, 2894-2900 (2016). https://oi.org/10.1039/c5sm02703a

[11] Kong D., Xiao X.: High cycle-life shape memory polymer at high temperature. Scientific Reports, 6, 33610/133610/10 (2016).

https://doi.org/10.1038/srep33610
[12] Wang Q., Bai Y., Chen Y., Ju J., Zheng F., Wang T.: High performance shape memory polyimides based on $\pi-\pi$ interactions. Journal of Materials Chemistry A, 3, 352-359 (2015). https://doi.org/10.1039/c4ta05058d

[13] Gao H., Li J., Xie F., Liu Y., Leng J.: A novel low colored and transparent shape memory copolyimide and its durability in space thermal cycling environments. Polymer, 156, 121-127 (2018). https://doi.org/10.1016/j.polymer.2018.10.001

[14] Yang Z., Chen Y., Wang Q., Wang T.: High performance multiple-shape memory behaviors of poly(benzoxazole-co-imide)s. Polymer, 88, 19-28 (2016). https://doi.org/10.1016/j.polymer.2016.02.001

[15] Qiu X., Xiao X., Kong D., Zhang W., Ma Z.: Facile control of high temperature shape memory polymers. Journal of Applied Polymer Science, 134, 44902/1-44902/6 (2017). https://doi.org/10.1002/app.44902

[16] Yang Z., Wang Q., Wang T.: Engineering a hyperbranched polyimide membrane for shape memory and $\mathrm{CO}_{2}$ capture. Journal of Materials Chemistry A, 5, 13823-13833 (2017). https://doi.org/10.1039/c7ta02842c

[17] Yang Z., Song F., Wang Q., Wang T.: Shape memory induced structural evolution of high performance copolyimides. Journal of Polymer Science Part A: Polymer Chemistry, 54, 3858-3867 (2016). https://doi.org/10.1002/pola.28356

[18] Koerner H., Strong R. J., Smith M. L., Wang D. H., Tan L-S., Lee K. M., White T. J., Vaia R. A.: Polymer design for high temperature shape memory: Low crosslink density polyimides. Polymer, 54, 391-402 (2013). https://doi.org/10.1016/j.polymer.2012.11.007

[19] Bai Y., Mao L., Liu Y.: High temperature shape memory polyimide ionomer. Journal of Applied Polymer Science, 133, 43630/1-43630/8 (2016). https://doi.org/10.1002/app.43630

[20] Xiao X., Kong D., Qiu X., Zhang W., Zhang F., Liu L., Liu Y., Zhang S., Hu Y., Leng J.: Shape-memory polymers with adjustable high glass transition temperatures. Macromolecules, 48, 3582-3589 (2015).

https://doi.org/10.1021/acs.macromol.5b00654

[21] Yang Z., Wang Q., Bai Y., Wang T.: AO-resistant shape memory polyimide/silica composites with excellent thermal stability and mechanical properties. RSC Advances, 5, 72971-72980 (2015). https://doi.org/10.1039/c5ra12293g

[22] Yoonessi M., Shi Y., Scheiman D. A., Lebron-Colon M., Tigelaar D. M., Weiss R. A., Meador M. A.: Graphene polyimide nanocomposites; Thermal, mechanical, and high-temperature shape memory effects. ACS Nano, 6, 7644-7655 (2012). https://doi.org/10.1021/nn302871y 
[23] Duarah R., Deka A., Karak N.: Multifaceted bioinspired hyperbranched polyurethane nanocomposite as a noncontact triggered self-healingmaterial. Express Polymer Letters, 14, 542-555 (2020).

https://doi.org/10.3144/expresspolymlett.2020.44

[24] Zhao R., Zhao T., Jiang X., Liu X., Shi D., Liu C., Yang S., Chen E-Q.: Thermoplastic high strain multishape memory polymer: Side-chain polynorbornene with columnar liquid crystalline phase. Advanced Materials, 29, 1605908/1-1605908/6 (2017).

https://doi.org/10.1002/adma.201605908

[25] Lan Z., Chen X., Zhang X., Zhu C., Yu Y., Wei J.: Transparent, high glass-transition temperature, shape memory hybrid polyimides based on polyhedral oligomeric silsesquioxane. Polymers, 11, 1058/1-1058/11 (2019). https://doi.org/10.3390/polym11061058

[26] Yao J., Zhang Z., Wang C., Ma S., Li T., Zhao X., Wang D., Zhou H., Chen C.: Multi-shape memory effect of polyimides with extremely high strain. RSC Advances, 7, 53492-53496 (2017). https://doi.org/10.1039/c7ra11399d

[27] Zhang X., Sun J., Fang S., Han X., Li Y., Zhang C.: Thermal, crystalline, and mechanical properties of octa(3chloropropylsilsesquioxane)/poly(L-lactic acid) hybrid films. Journal of Applied Polymer Science, 122, 296303 (2011).

https://doi.org/10.1002/app.34059

[28] Xie T.: Tunable polymer multi-shape memory effect. Nature, 464, 267-270 (2010).

https://doi.org/10.1038/nature08863
[29] Yakacki C. M., Shandas R., Lanning C., Rech B., Eckstein A., Gall K.: Unconstrained recovery characterization of shape-memory polymer networks for cardiovascular applications. Biomaterials, 28, 2255-2263 (2007).

https://doi.org/10.1016/j.biomaterials.2007.01.030

[30] Gall K., Yakacki C. M., Liu Y., Shandas R., Willett N., Anseth K. S.: Thermomechanics of the shape memory effect in polymers for biomedical applications. Journal of Biomedical Materials Research Part A, 73, 339-348 (2005). https://doi.org/10.1002/jbm.a.30296

[31] Luo Y., Guo Y., Gao X., Li B-G., Xie T.: A general approach towards thermoplastic multishape-memory polymers via sequence structure design. Advanced Materials, 25, 743-748 (2013). https://doi.org/10.1002/adma.201202884

[32] Li X., Ma H., Shen Y., Hu W., Jiang Z., Liu B., Guiver M. D.: Dimensionally-stable phosphoric acid-doped polybenzimidazoles for high-temperature proton exchange membrane fuel cells. Journal of Power Sources, 336, 391-400 (2016). https://doi.org/10.1016/j.jpowsour.2016.11.013

[33] Li X., Feng R., Xu Y., Li Y., Zhang Q.: Shape memory hierarchical AB copolymer networks. Polymer Chemistry, 11, 909-921 (2020). https://doi.org/10.1039/C9PY01567A 